\title{
Properties of Films Obtained from Biopolymers of Different Origins for Skin Lesions Therapy
}

\author{
Márcia Zilioli Bellini ${ }^{1,2}$, Pedro de Oliva-Neto ${ }^{3}$ and Ângela Maria Moraes ${ }^{2 *}$ \\ ${ }^{1}$ Departamento de Engenharia de Alimentos; Faculdades Adamantinenses Integradas; Adamantina - SP - Brasil. \\ ${ }^{2}$ Departamento de Engenharia de Materiais e de Bioprocessos; Faculdade de Engenharia Química; Universidade \\ de Campinas; Campinas - SP - Brasil. ${ }^{3}$ Departamento de Ciências Biológicas; Universidade Estadual Paulista; \\ Assis - SP - Brasil
}

\begin{abstract}
In this study, the effects of the origin of xanthan used, in combination with chitosan, to prepare films for the treatment of skin lesions were evaluated. The characteristics of the films obtained with xanthan commercially available for the food industry sector and xanthan originated from a fermentation process conducted in a pilot plant were compared. Results showed that the source did not strongly interfere in many of the properties of the films, such as the mechanical properties, cytotoxicity to L929 cells, absorption of simulated body fluid and culture medium, stability in water and saline solution. Hence, even though the properties of biopolymers of different sources might vary, the films prepared with two distinct types of xanthan gum could be considered as potentially safe and similar in terms of relevant characteristics considering the aimed application.
\end{abstract}

Key words: biomaterials, biopolymers, films, membranes, properties and characterization, biomedical applications

\section{INTRODUCTION}

The use of biopolymers for the production of material intended for medical and pharmaceutical applications, targeting, for example, the controlled release of bioactive agents, tissue engineering and cell therapy has increased in recent years due to the availability, biocompatibility and biodegradability of the many compounds in this category (Bueno and Moraes 2011). Polysaccharides such as chitosan (C), xanthan (X) and alginate are examples of non-toxic natural polymers used in the composition of materials for this purpose, being used alone or in combination with each other or with other compounds (Popa et al. 2010; Fernandes et al. 2011; Bellini et al. 2012; Veiga and Moraes 2012). However, a major obstacle to their use is the variability in the characteristics of molecules resulting from different sources, which may result in changes in the properties of biomaterials obtained when these polymers are used.

Chitosan is a biopolymer with cationic character, having a linear structure similar to that of the glycosaminoglycans of cartilage (Silva et al. 2010). It is derived from chitin, being formed by glucosamine and $\mathrm{N}$-acetyl-D-glucosamine monomers linked by glycoside bonds $\beta(1 \rightarrow 4)$ (Jayakumar et al. 2011; Coma 2013). Its production process is relatively simple and one of its most important characteristics regarding biological applications is its degree of deacetylation. This polymer is soluble in aqueous acidic solutions, resulting in structures with different dimensions and geometric configurations, such as films, particles, fibers, and

*Author for correspondence: ammoraes@ @eq.unicamp.br 
gels (Santos et al. 2003; Ragetly et al. 2010). The polycationic nature of chitosan enables its association with polymers with negative charges such as alginate (Rodrigues et al. 2008; Bueno and Moraes 2011), dextran derivatives (Fukuda et al. 1978), polyesters (Silva et al. 2010), silk fibers (She et al. 2008), gelatin (Liu et al. 2004; Yin et al. 2005), and xanthan gum (Eftaiha et al. 2009; Bellini et al. 2012; Veiga and Moraes 2012), resulting in stable polyelectrolyte complexes.

Xanthan gum is a water-soluble exopolysaccharide synthesized by Xanthomonas and is used as emulsifier, suspension stabilizer, flocculant, gelling and viscosity agent. It is widely used in different industrial applications (Oliveira et al. 2013), such as in food, toiletry, oil recovery, pharmaceutical and cosmetics industry. It is commonly used in the form of gels or films (Bejenariu et al. 2008). Its main chain is equivalent to that of cellulose, consisting of $\mathrm{D}$ glucose units linked together by $\beta(1 \rightarrow 4)$ bonds, and its side chains are composed of alternating residues of D-mannose and D-glucuronic acid in the ratio 2:1 (Oliva-Neto et al. 2011). Commercially, xanthan gum is the most economically relevant bacterial polysaccharide (Meyer et al. 2008). It is estimated that by 2015, the world production of xanthan gum may reach 80,000 tons, associated to a market of around 400 million dollars (Carignatto et al. 2011), but new applications in the pharmaceutical field may expand this scenario further.

When compared to polysaccharides extracted directly from the natural sources, such as alginate derived from seaweed, xanthan gum has the advantage of being independent of the production site and climatic conditions, which allows its production under significantly more controlled conditions, with lower variability in the properties of material originated from different batches and, therefore, with higher quality assurance. For this reason, xanthan gum, alone or combined with other polymers, has been gaining attention in the composition of biomaterials intended for different biomedical applications, such as devices for the controlled release of drugs (Popa et al. 2010; Bellini et al. 2012; Veiga and Moraes 2012; Dyondi et al. 2013) and probiotic bacteria (Argin et al. 2014), hydrogels for bone regeneration (Izawa et al. 2014), ophthalmological materials (Ceulemans et al. 2002; Ludwig 2005), implants (Kumar et al. 2007) and scaffolds for tissue engineering (Silva et al. 2007; Bellini et al. 2012).
Various strategies to improve the production of xanthan have been investigated to reduce its cost of manufacture, especially the selection of cell cultures with high capacity (Oliveira et al. 2000) and the proposition of culture media with different formulations (Carignatto et al. 2011; Diniz et al. 2012).

Promising results for the use of scaffolds based on polysaccharides and other polymers of natural origin in the regeneration of skin lesions have been reported (Liu et al. 2004; Chen et al. 2009; Pajoum et al. 2009). In fact, skin substitutes obtained by tissue engineering represent today a real therapeutic option for severe burns and other skin injuries. Apligraf ${ }^{\circledR}$ (produced by the company Organogenesis) and OrCel (from Forticell Bioscience) scaffolds consisting of type I bovine collagen inoculated with human keratinocytes and fibroblasts are examples of devices for tissue engineering already approved by the Food and Drug Administration (FDA, USA).

Scaffolds of chitosan-gelatin-hyaluronic acid (Liu et al. 2004) and of chitosan-collagen (Pajoum et al. 2009) are also useful in the co-culture of keratinocytes and fibroblasts aiming at obtaining artificial skin. Such devices are flexible and have good mechanical properties, facilitating skin regeneration. Porous chitosan-collagen matrices are particularly promising in the tissue engineering context, being reported, for example, that their implantation in rabbits' ears results in rapid infiltration of fibroblasts in the treated region (Ma et al. 2003). However, given that there is a tendency to avoid the use of materials from xenogenic origin for tissue engineering purposes and of complex composition, collagen replacement by compounds such as xanthan gum could provide additional benefits to such devices.

The carboxyl groups in xanthan gum, when combined with the amines of chitosan, result in a microenvironment that favors the stabilization of proteins (Chellat et al. 2000) and allows obtaining hydrogels (Dyondi et al. 2013; Izawa et al. 2014), tablets (Popa et al. 2010) and films (Bejenariu et al. 2008). The properties of membranes of chitosan combined with analytical grade xanthan gum in different reacting conditions were assessed in detail recently by Bellini et al. (2012), which showed that these devices had appropriate characteristics for application as bioactive dermal dressings and as three-dimensional scaffolds for cell culture useful in the tissue engineering area. 
Thus, considering the relevance of the search for natural polymers of low cost, safe and with more reproducible properties useful in the manufacturing biomaterials, the purpose of the present work was to evaluate whether films obtained by combining chitosan with xanthan gum of different sources would have equivalent performance. In this context, the use of a xanthan gum commercially available for the food industry sector and of a xanthan gum obtained through a Brazilian fermentation technology process using sucrose and ethanol from sugar cane (Carignatto et al. 2011) carried out in a pilot plant unit located at the São Paulo State University (UNESP) at Assis, São Paulo, Brazil were analyzed. The characteristics of these formulations were also compared to those shown by higher cost films produced with analytical grade xanthan gum. It was expected that the origin of the xanthan gum would not interfere substantially on relevant properties of the biomaterial, aiding in the consolidation of the use of this polysaccharide for the particular purpose aimed.

\section{MATERIAL AND METHODS}

\section{Material}

Chitosan-xanthan films were produced using chitosan (C) with a deacetylation degree in the range of 75 to $85 \%$ (batch number 9012-76-4, Sigma-Aldrich, St. Louis, MO), glacial acetic acid (Merck, São Paulo, Brazil) and xanthan gum from two different sources, the first $\left(\mathrm{X}_{\mathrm{Keltrol}}\right)$ commonly used as an additive in food processing (Keltrol ${ }^{\circledR}$ type xanthan gum, available from CP Kelco, Brazil), while the second $\left(\mathrm{X}_{\text {pilot }}\right)$ was produced locally in a pilot plant using a technology developed at the São Paulo State University (UNESP) (Carignatto et al. 2011). The water used was distilled and deionized in a MilliQ Millipore system.

\section{Preparation of the Films}

The chitosan-xanthan gum films were prepared according to the procedures described by Bellini et al. (2012), using a mass ratio of chitosan to xanthan equal to $1: 1$. An aliquot of $100 \mathrm{~mL}$ of $1 \%$ chitosan (w/v) in $2 \%(\mathrm{v} / \mathrm{v})$ acetic acid was added to $100 \mathrm{~mL}$ of xanthan $1 \%(\mathrm{w} / \mathrm{v})$ aqueous solution using a peristaltic pump (Model TE 184 Tecnal, Brazil) at a flow rate of $10 \mathrm{~mL} \min ^{-1}$ stirred at $1000 \mathrm{rpm}$ using a mechanical mixer (Model TE
038 Tecnal, Brazil) in a glass reactor at $25^{\circ} \mathrm{C}$ with an internal diameter of $11 \mathrm{~cm}$. The obtained suspension was deaerated for $2 \mathrm{~h}$ using a vacuum pump (Model TE 058 Tecnal, Brazil), transferred to a polystyrene Petri dish (15 cm in diameter) and dried in an air circulating oven (Model TE 394/1, Tecnal, Brazil) at $37^{\circ} \mathrm{C}$ until constant weight for approximately $24 \mathrm{~h}$.

The dried films were washed with $500 \mathrm{~mL}$ of deionized water for $30 \mathrm{~min}$ three times to remove the residual acetic acid. Then, the samples were immersed in $200 \mathrm{~mL}$ of $10 \mathrm{mM}$ Hepes buffer for $30 \mathrm{~min}$ and again in $500 \mathrm{~mL}$ of water for $30 \mathrm{~min}$. afterwards, the films were dried at $37^{\circ} \mathrm{C}$ for $24 \mathrm{~h}$. The films were cut into appropriate size samples and sterilized by exposure to Oxyfume-30 (30\% ethylene oxide and $70 \%$ carbon dioxide) at $40^{\circ} \mathrm{C}$ for $8 \mathrm{~h}$ and relative humidity of 30 to $80 \%$ at Acecil Central de Esterilização Comércio e Indústria Ltda (Campinas, SP, Brasil). The residual ethylene oxide was removed by keeping the samples under air circulation for $48 \mathrm{~h}$.

\section{Characterization of the Films}

The samples were characterized with respect to morphology, thickness, absorption and stability in aqueous solutions, mechanical properties, volumetric expansion and cytotoxicity as described below.

\section{Morphology}

The overall aspect was analyzed by inspection with the naked eye and recorded using a digital camera. The surface morphology and the cross section of the films were examined by scanning electron microscopy (SEM, Leo 440i model, Leica). Samples of $2 \mathrm{~cm} \times 1 \mathrm{~cm}$ were freeze-dried, fixed to proper supports and coated with gold (Sputter mini SC 7620) prior to the analysis.

\section{Thickness}

The thickness of the films was measured with a micrometer (Digimess) in seven equidistant positions near the edge of each film. The results were expressed as mean values.

\section{Mechanical Properties}

The mechanical properties of the films were evaluated based on ASTM D-882 (1995) using eight independent samples $(2.54 \mathrm{~cm} \times 10 \mathrm{~cm})$ for each film formulation. A texturometer (TA.XT2 model, Stable Micro System SMD, England) with initial grip separation of $5 \mathrm{~cm}$ and crosshead speed 
of $1 \mathrm{~cm} / \mathrm{s}$ equipped with a cell load of $5 \mathrm{kgf}$ was used for this analysis. The tension $(T)$ and elongation $(E)$ at break were calculated through Equations 1 and 2, respectively:

$$
\begin{aligned}
& T=\frac{F_{m}}{A_{s}} \\
& E=\frac{d_{r}-d_{i}}{d_{1}} \times 100
\end{aligned}
$$

where $F_{m}$ is the maximum strength, $A_{s}$ is the crosssectional area of the sample, $d_{i}$ is the initial distance between the texturometer grips $(5 \mathrm{~cm})$ and $d_{r}$ is the distance between the grips at the moment of sample rupture.

\section{Absorption and Stability in Aqueous Solutions}

The degree of absorption of different aqueous solutions by the films was evaluated based on the method proposed by Rodrigues et al. (2008). Samples $(1 \mathrm{~cm} \times 6 \mathrm{~cm})$ dried at $37^{\circ} \mathrm{C}$ with a known mass $\left(M_{i}\right)$ were immersed in $7.0 \mathrm{~mL}$ of water, saline solution (SS) consisting of $0.9 \%$ $(\mathrm{w} / \mathrm{v}) \mathrm{NaCl}$ in water, simulated body fluid (SBF) prepared according to Kokubo et al. (1990), RPMI culture medium (Nutricell, Brazil) supplemented with 0.3 g. $\mathrm{L}^{-1}$ of L-glutamine, $2 \mathrm{~g}$. $\mathrm{L}^{-1}$ of $\mathrm{D}-$ glucose, $2 \mathrm{~g}$. $\mathrm{L}^{-1}$ of $\mathrm{NaHCO}_{3}, 10,000 \mathrm{IU} \mathrm{L}^{-1}$ of penicillin, $0.05 \mathrm{~g}$. $\mathrm{L}^{-1}$ of streptomycin, $5.96 \mathrm{~g}$. $\mathrm{L}^{-1}$ of Hepes and $10 \% \quad(\mathrm{v} / \mathrm{v})$ fetal bovine serum (Nutricell, Brazil). The final mass $\left(M_{f}\right)$ of the samples exposed to water, SS and SBF were determined after $24 \mathrm{~h}$ or after $144 \mathrm{~h}$ when in contact with supplemented RPMI culture medium. The degree of swelling $(S)$ was calculated using Equation 3:

$$
S=\frac{M_{f}-M_{i}}{M_{i}} \times 100
$$

Afterwards, the wet samples were dried at $37^{\circ} \mathrm{C}$ for $10 \mathrm{~h}$ and their final mass $\left(\mathrm{M}_{\mathrm{d}}\right)$ were measured to determine their stability in each solution $(E)$ with respect to variation of mass, as shown in Equation 4:

$$
E=\frac{\left(M_{i}+M_{s o l}\right)-M_{d}}{M_{i}} \times 100
$$

where $M_{\text {sol }}$ refers to the mass of soluble compounds present in the solutions incorporated by the samples, equal to $9.0 \mathrm{~g} \mathrm{~L}^{-1}, 15.3 \mathrm{~g} \mathrm{~L}^{-1}$ and $19.3 \mathrm{~g} \mathrm{~L} \mathrm{~L}^{-1}$ respectively for $\mathrm{SS}, \mathrm{SBF}$ and supplemented RPMI culture medium. All analysis was performed in at least triplicate.

\section{Volume Expansion in Cell Culture Medium}

The degree of tridimensional expansion of the films was determined indirectly based on the method proposed by Zeng and Ruckenstein (1996), quantifying the amount of culture medium, which presumably occupied the pores of saturated samples. Dry samples $(2 \mathrm{~cm} \times 4 \mathrm{~cm})$ with known mass $\left(M_{i}\right)$ were immersed in $10 \mathrm{~mL}$ of supplemented RPMI culture medium at $37^{\circ} \mathrm{C}$ for $24 \mathrm{~h}$. Then, the masses of the hydrated samples $\left(M_{f}\right)$ and their dimensions were determined. The degree of volumetric expansion $(\varepsilon)$ was calculated according to Equation 5, where $d_{\text {solv }}$ was the density of the culture medium at $37^{\circ} \mathrm{C}$ and $V$ was the volume of the sample in the saturated state:

$$
\varepsilon(\%)=\frac{\left(\frac{M_{f}-M_{i}}{d_{\text {solv }}}\right)}{V} \times 100
$$

\section{In Vitro Cytotoxicity}

The in vitro toxicity of the films was assessed indirectly by exposing L929 fibroblasts to aqueous extracts of the films and by subsequent determination of mitochondrial activity of the cells with 3-(4,5-dimethylthiazol-2-yl)-2,5diphenyl tetrazolium bromide indicator (MTT, Sigma Chemical, St. Louis, MO) in at least quintuplicate. The extracts were obtained by incubating the films in supplemented RPMI culture medium at a concentration equal to $0.05 \mathrm{~g}$ of dry material per milliliter of medium for $48 \mathrm{~h}$ at $37^{\circ} \mathrm{C}$ and $5 \% \mathrm{CO}_{2}$ (Bellini et al. 2012).

Aliquots of $100 \mu \mathrm{L}$ of $\mathrm{L} 929$ cells containing $1 \times 10^{5}$ cells $\mathrm{mL}^{-1}$ in supplemented RPMI medium obtained by trypsinization $(2.5 \%$ trypsin containing EDTA, Nutricell, Brazil) of cells near confluence in monolayer culture were inoculated into each well of flat bottom 96-wells plates (TPP). The plates were kept in an incubator at $37^{\circ} \mathrm{C}$ in the presence of $5 \% \mathrm{CO}_{2}$ for $24 \mathrm{~h}$ and then the culture medium of each well was replaced with $100 \mu \mathrm{L}$ of extracts of films. The cells were again incubated for $24 \mathrm{~h}$ and then the extracts were removed and the wells were washed twice with $100 \mu \mathrm{L}$ of phosphate buffer (PBS) containing ethylenediaminetetraacetic acid (EDTA). Aliquots of $100 \mu \mathrm{L}$ of supplemented RPMI medium were added to each well together with $10 \mu \mathrm{L}$ aliquots of MTT at $5.0 \mathrm{mg} \mathrm{mL}^{-1}$ in PBS-EDTA solution. After $4 \mathrm{~h}$ incubation at $37^{\circ} \mathrm{C}, 100 \mu \mathrm{L}$ of a solution of sodium dodecyl sulfate (Sigma Chemical, St. Louis, MO) at $100 \mathrm{~g} \mathrm{~L}^{-1}$ dissolved in a solution of dimethyl sulfoxide (Sigma Chemical, St. Louis, 
MO) containing $0.6 \%$ of acetic acid (Merck, São Paulo, Brazil) were added to each well. The samples were homogenized and the cells returned to the incubator at $37^{\circ} \mathrm{C}$ for one hour. After this period, the absorbance of the samples was analyzed in a microplate spectrophotometer at 620 nm (Thermo Scientific Multiskan FC, Finland). Extracts of culture plate fragments and of latex (in the form of amber tourniquet tubes regularly used in blood drawing) were used as negative and positive controls of cytotoxicity, respectively, and culture medium without cells was used as blank.

\section{RESULTS AND DISCUSSION}

The choice of a source of raw material for the production of a given biomaterial must take into account factors such as biocompatibility, cost, ease of access and performance regarding the desired purpose. In this context, biopolymers readily available by fermentation with assured quality are especially attractive, such as xanthan gum. Films prepared by the combination of chitosan and xanthan from two different sources available in Brazil, one produced on a pilot plant with technology developed at the University of the State of São Paulo at Assis (Carignatto et al. 2011) and the other (Keltrol $^{\circledR}$ type, from CP Kelco, Brazil) used by food industries. Several characteristics important regarding the application of these films as wound dressings were evaluated and compared with results obtained previously ${ }^{3}$ for a formulation based on xanthan of analytical origin.

\section{Aspect of the Films}

The results of the analysis of the films regarding their aspect are shown in Figures 1 and 2. No major visual differences were observed between the films prepared with xanthan from the different sources, as shown in Figures 1A and 1B. The two formulations were relatively homogeneous before drying, initially presenting high concentrations of trapped air bubbles due to the high viscosity of the material; however, despite bubble coalescence apparently occurred during the drying process, the remaining bubbles did not cross the film thickness. When fully dried, the formulations resulted in thin, flexible films, with rippled surfaces, as described by Bellini et al. (2012) for films prepared with xanthan of analytical grade and chitosan at a 1:1 mass ratio. Both formulations were translucent, but better transparency was observed for the films containing $X_{\text {pilot }}$ instead of $X_{\text {Keltrol }}$ (Fig $1 \mathrm{C}$ and D), and this particular feature was fairly important when considering application as dermal wound dressings, given that it would allow effective inspection of the wound bed during the recovery process without removing the film.

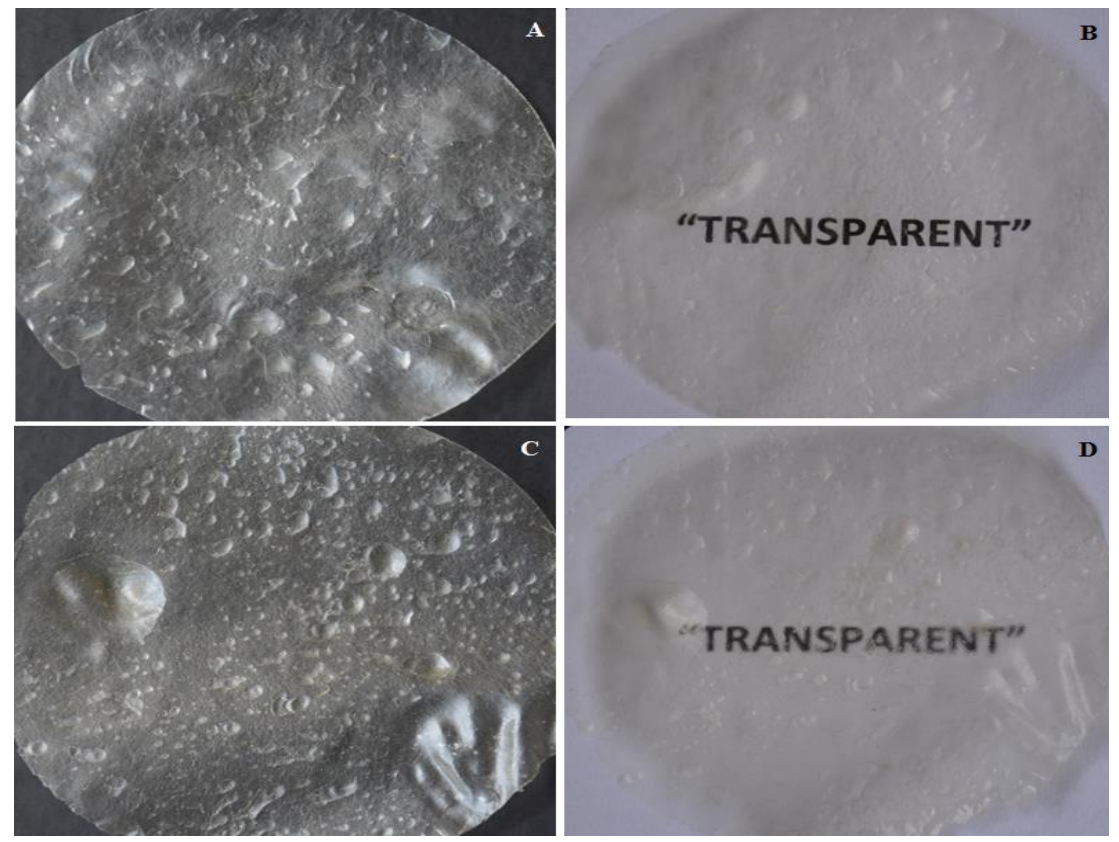

Figure 1 - Typical morphology of chitosan-xanthan films regarding the visual aspect: (A and B) C- $X_{\text {pilot }}$ films; (C and D) C- $X_{\text {Keltrol }}$ films. 
Typical results of the SEM analysis showed the presence of fibrillar structures homogeneously distributed over the surface of the films (Figs 2A and 2B). The integrity of the surface layer is critical in dermal dressings, allowing them to act as a barrier against the entry of infecting microorganisms in the skin lesions. The cross section analysis also showed that the films had lamellar structure, in accordance with observations for chitosan-alginate membranes (Wang et al. 2002; Rodrigues et al. 2008) and for C-X films prepared with xanthan gum of analytical grade (Bellini et al. 2012) and with $X_{\text {Keltrol }}$ obtained in different conditions (Veiga and Moraes 2012). Differences in the matrix packing along the thickness of the films can be also observed in Figures $2 \mathrm{~A}$ and $2 \mathrm{~B}$.

\section{Physico-Chemical Characterization of the Films}

Data on the mean thickness, swelling behavior and stability regarding mass loss in different aqueous solutions, mechanical properties and volumetric expansion of the films obtained are shown in Table 1 . The dry films were 104.3 to $127.1 \mu \mathrm{m}$ in thickness (Table 1). This is a relevant property in the architecture of the matrix, and may interfere not only with the comfort to the patient but also with the transport of gases such as $\mathrm{O}_{2}, \mathrm{CO}_{2}$, nutrients and metabolites in the wound region. Generally, devices used as dermal substitutes and in skin tissue engineering are thinner than the human dermis (Ma et al. 2001), which ranges between 500 and $2000 \mu \mathrm{m}$ in thickness. In this context, both types of film formulations were suitable.

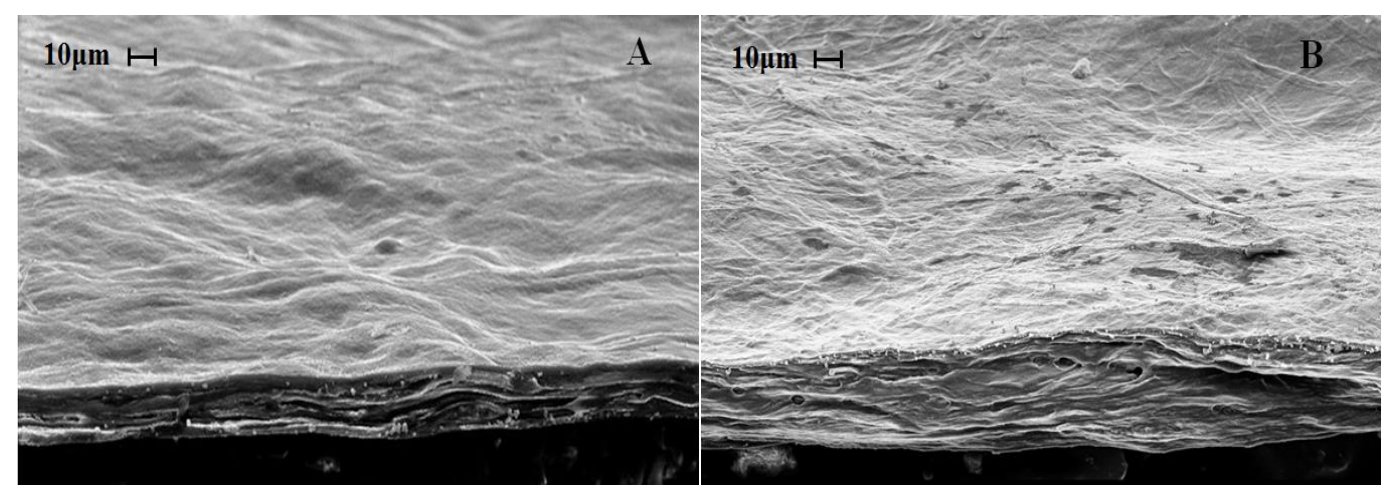

Figure 2 - SEM analysis of films obtained by combining chitosan to $\mathrm{X}_{\text {pilot }}(\mathrm{A})$ or $\mathrm{X}_{\mathrm{Keltrol}}(\mathrm{B})$.

Table 1 - Characteristics of membranes obtained from chitosan combined with xanthan gum of different sources: mean thickness values, mechanical properties, absorption and stability in aqueous solutions, and volumetric expansion in supplemented RPMI culture medium.

\begin{tabular}{|c|c|c|c|}
\hline \multirow{2}{*}{\multicolumn{2}{|c|}{ Property }} & \multicolumn{2}{|c|}{ Membrane formulation } \\
\hline & & C-X pilot $_{\text {pil }}$ & C-X Keltrol \\
\hline Thickness $(\mu \mathrm{m})$ & & $104.3 \pm 15.1^{\mathrm{a}}$ & $127.1 \pm 5.0^{b}$ \\
\hline \multirow{2}{*}{$\begin{array}{l}\text { Mechanical properties } \\
\text { of dry samples }\end{array}$} & Tensile strenght $(\mathrm{MPa})$ & $12.7 \pm 2.0^{\mathrm{c}}$ & $15.7 \pm 5.0^{\mathrm{c}}$ \\
\hline & Elongation at break (\%) & $2.1 \pm 0.3^{\mathrm{d}}$ & $2.1 \pm 0.4^{\mathrm{d}}$ \\
\hline \multirow{4}{*}{$\begin{array}{l}\text { Absorption of different aqueous } \\
\text { solutions }(\mathrm{g} / \mathrm{g})\end{array}$} & $\mathrm{H}_{2} \mathrm{O}(24 \mathrm{~h})$ & $58.5 \pm 4.0^{\mathrm{e}}$ & $92.0 \pm 2.7^{\mathrm{t}}$ \\
\hline & SS (24h) & $3.9 \pm 0.3^{\mathrm{g}}$ & $17.6 \pm 0.7^{\mathrm{h}}$ \\
\hline & SBF (24 h) & $13.0 \pm 1.0^{1}$ & $8.9 \pm 0.1^{1}$ \\
\hline & RPMI (144 h) & $6.9 \pm 0.4^{\mathrm{j}}$ & $5.2 \pm 0.8^{\mathrm{j}}$ \\
\hline \multirow{4}{*}{$\begin{array}{l}\text { Mass loss in different aqueous } \\
\text { solutions }(\%)\end{array}$} & $\mathrm{H}_{2} \mathrm{O}(24 \mathrm{~h})$ & $25.5 \pm 1.9^{\mathrm{K}}$ & $20.7 \pm 33.0^{\mathrm{K}}$ \\
\hline & SS (24 h) & $15.7 \pm 0.9^{\mathrm{m}}$ & $11.2 \pm 1.5^{\mathrm{m}}$ \\
\hline & SBF (24 h) & $17.7 \pm 1.3^{\mathrm{n}}$ & $10.2 \pm 0.4^{\circ}$ \\
\hline & RPMI (144 h) & $25.5 \pm 3.4^{\mathrm{p}}$ & $14.9 \pm 1.0^{\mathrm{q}}$ \\
\hline \multicolumn{2}{|c|}{ Volume expansion in RPMI culture medium (\%) } & $96.5 \pm 5.3^{\mathrm{r}}$ & $84.5 \pm 3.3^{\mathrm{r}}$ \\
\hline
\end{tabular}


Thin films and scaffolds with composition based in the use of polysaccharides are described in the literature, but only a few of them deal with the mixture chitosan-xanthan gum. Porous chitosan scaffolds with thickness between 60 and $80 \mu \mathrm{m}$ produced by lyophilization proved to be appropriate for the in vitro culture of dermal fibroblasts, showing also to be potentially suitable for the use in skin tissue engineering (Ma et al. 2001). Chitosan-alginate membranes designed for treating skin lesions had thicknesses between 23.5 and $80 \mu \mathrm{m}$ (Wang et al. 2001; Ragetly et al. 2010). Films of chitosan complexed with xanthan gum of analytical grade at $\mathrm{C}: \mathrm{X}$ mass ratios of $1: 1$ and 1.2:0.8 had mean thickness varying from 100 to $200 \mu \mathrm{m}$ (Bellini et al. 2012), similar to membranes prepared by combining $\mathrm{C}-\mathrm{X}_{\text {Keltrol }}$ in different conditions from those used in the present work, being, therefore, in the same range of the values reported herein.

In addition to proper thickness, modulus of elasticity and tensile strength compatible with the damaged tissue are important requirements of materials used in tissue regeneration. The tensile strength of the prepared films ranged from 12.7 to 15.7 $\mathrm{MPa}$, while elongation at break was $2.1 \%$ (Table 1). The values of tensile strength obtained were lower than those of films prepared with chitosan and xanthan gum of analytical grade, equal to 25.1 MPa (Bellini et al. 2012). However, the attained values were higher than those of lamellar membranes of chitosan-alginate (6.9 MPa) (Rodrigues et al. 2008) and also of films prepared with chitosan and xanthan gum of the Keltrol $^{\circledR}$ type at 1:1 mass ratio processed at different flow rates (2.2 to $5.2 \mathrm{MPa}$ ) (Veiga and Moraes 2012) or at the 1.2:0.8 proportion (8.7 MPa) (Bellini et al. 2012). Similarly, films prepared only with chitosan or with chitosan combined with chitin had low tensile strength, varying between 3.0 and $6.5 \mathrm{MPa}$ (Dallan et al. 2007). As the values of tensile obtained for both $\mathrm{C}-\mathrm{X}_{\mathrm{pilot}}$ and $\mathrm{C}-\mathrm{X}_{\mathrm{Keltrol}}$ formulations were in the range expected for normal skin (2.1 to $21 \mathrm{MPa})$ (Wang et al. 2002; Jussila et al. 2005), the films obtained seemed adequate for use as dermal dressings also considering this requirement.

Regardless of the type of xanthan used, however, the elongation at break of the films was low (around 2\%), not reaching the values reported (Hansen and Jemec 2002; Jussila et al. 2005) for normal skin, from 61 to $70 \%$. The low elongation, however, did not disqualify biomaterials for application in the regeneration of skin, only indicated that they would not be recommended for the regions with high mechanical requirements, such as knees and elbows. The low elongation of biomaterials prepared with chitosan and applicable as dermal dressings has been reported in the literature. Dressings and porous films prepared with chitosan and chitosan-alginate showed low elongations, between 0.8 and $3.8 \%$ (Lai et al. 2003; Kucharska et al. 2008; Bueno and Moraes 2011). Membranes prepared with chitosan and analytical grade xanthan gum also had low elongation at break values, ranging between 1.1 and $2.0 \%$ (Bellini et al. 2012), as well as C- $\mathrm{X}_{\text {Keltrol }}$ films prepared at different flow rates (1.2 to $2.5 \%$, according to Veiga and Moraes 2012). In addition, moisture can significantly increase the elongation capacity of the films due to the plasticizer effect of the water in contact with the polysaccharides, circumventing the problem at least partially.

Suitable absorption and stability in the presence of physiological fluids are also important characteristics of biomaterials intended for skin regeneration. Water or saline can be employed, for example, to hydrate the films before their use on the patient and, when in contact with exudative lesions, the dressing should be able to quickly absorb the liquid without losing weight due to disintegration. If the films are considered to be used as scaffolds for skin tissue engineering, appropriate behavior of the biomaterials in culture media commonly used for this purpose would also be expected.

High absorption of water was noticed for the films of both formulations (Table 1). However, the biomaterial obtained with $\mathrm{X}_{\mathrm{Keltrol}}$ showed significantly higher uptake of water $\left(92.0 \mathrm{~g} \mathrm{H}_{2} \mathrm{O} / \mathrm{g}\right.$ dry film) than the one prepared with $\mathrm{X}_{\text {pilot }}(58.5$ $\mathrm{g} / \mathrm{g}$ ), behaving similarly to membranes prepared alike but with analytical grade xanthan gum (Bellini et al. 2012) (85.5 g/g). High water absorption was also reported for the hydrogels prepared with chitosan and xanthan aiming at the controlled release of drugs (64 $\mathrm{g}$ of water per gram of hydrogel) (Popa et al. 2010) and for lamellar films prepared at a $\mathrm{C}: \mathrm{X}$ mass ratio of 1.2:0.8 (48.9 $\mathrm{g}_{2} \mathrm{O}$ per gram of dry material) (Bellini et al. 2012). Although the material prepared with $X_{\text {pilot }}$ absorbed less water than the ones obtained with $\mathrm{X}_{\text {Keltrol}}$, the performance obtained was satisfactory for the proposed application (regeneration of skin), being still higher than that of chitosan-alginate films intended as dermal dressings (Yan et al. 
2000; Dallan et al. 2007; Rodrigues et al. 2008), varying from 9.5 to $19.2 \mathrm{~g} \mathrm{H}_{2} \mathrm{O} / \mathrm{g}$ dry film, and also of C-X films prepared at different flow rates (Veiga and Moraes 2012) (between 15.9 and 39.4 $\mathrm{g} \mathrm{H}_{2} \mathrm{O} / \mathrm{g}$ dry film) and of chitosan-xanthan porous films (Bellini et al. 2012) prepared in the presence of the surfactants Tween 80 and Pluronic F68 (34.1 and $29.8 \mathrm{~g} \mathrm{H}_{2} \mathrm{O} / \mathrm{g}$ dry film, respectively). The absorption of $\mathrm{NaCl}$ and $\mathrm{SBF}$ is not as high as that observed for water, but no less important. Higher approximation between the chains of polysaccharides is expected in the solutions containing salts due to their high ionic strength, which would hinder the penetration of water into the film structure (Bueno and Moraes 2011).

Appropriate absorption of cell culture medium by a dressing or bioactive scaffold is also desirable, since it would allow higher availability of nutrients to the cells grown therein. The films studied showed statistically similar supplemented RPMI culture medium uptake values (Table 1), equal to 6.9 and $5.2 \mathrm{~g}$ of medium per gram of dry film, respectively for membranes obtained with $X_{\text {pilot }}$ and $\mathrm{X}_{\text {Keltrol. }}$. These values were directly comparable to that observed for membranes produced with the combination of chitosan and xanthan gum of $6.3 \mathrm{~g}$ supplemented RPMI per gram of dry film (Bellini et al. 2012). However, more limited capacity of three-dimensional expansion in this culture medium was noted for the devices made with xanthan of analytical grade (77.1\%) (Bellini et al. 2012) when compared to the samples prepared with $X_{\text {pilot }}(96.5 \%)$ or $X_{\text {Keltrol }}(84.5 \%)$. These results indicated important advantages achieved with these formulations, namely increased availability of space for the accommodation of the cells inoculated in the biomaterials produced with $X_{\text {pilot }}$ and $X_{\text {Keltrol }}$ and potential for reducing the mass transport limitations related to both the supply of nutrients and removal of metabolites toxic to the cells.

One of the differences between the types of xanthan gum used is their viscosity. While a $1 \%$ aqueous solution of $X_{\text {pilot }}$ has a viscosity of 1600 $\mathrm{cP}$, an equivalent solution of $\mathrm{X}_{\text {Keltrol }}$ presents a viscosity of $1480 \mathrm{cP}$. In comparison to the analytical grade xanthan, which has a viscosity between 800 and $1200 \mathrm{cP}$ for a solution of the same concentration (data from the supplier), both alternative biopolymers are constituted of large chains, what would explain the higher capacity of $\mathrm{X}_{\text {pilot }}$ and $\mathrm{X}_{\mathrm{Keltrol}}$-containing membranes to expand in culture medium, a property of paramount importance in a scaffold (Yang et al. 2010).

Once in contact with living organisms, biodegradable scaffolds may suffer severe degradation, therefore, the analysis of the stability of the biomaterial exposed to different aqueous media and also to cell culture medium is of great relevance. Table 1 showed that the films analyzed remained reasonably stable when in contact with the aqueous solutions tested. The film prepared with $X_{\text {pilot }}$ showed the highest tendency to disintegrate, with maximum mass loss in water and culture media around $26 \%$, in comparison to the formulation containing $X_{\text {Keltrol, }}$ which had a mass loss of $21 \%$ in water and of $15 \%$ in culture medium, values similar to those obtained for a formulation consisting of chitosan complexed with analytical grade xanthan (Bellini et al. 2012), equal to $14 \%$ in when exposed to water and $17 \%$ in culture medium. These values were also close to those reported by Rodrigues et al. (2008) for chitosan-alginate membranes in water (maximum mass loss of 20\%) and by Veiga and Moraes (2012) for C- $X_{\text {Keltrol }}$ membranes (maximum loss of $13 \%$ in SBF, $10 \%$ in water and $4 \%$ in saline solution).

The larger mass losses were observed in water and culture medium, perhaps due to the $\mathrm{pH}$ variation within the matrix. The $\mathrm{pH}$ of the culture medium and of water were close to seven and given that the average $\mathrm{pKa}$ values of chitosan and xanthan were 6.3 (Malafaya et al. 2007) and 2.9, respectively (Rodd et al. 2001), it could be presumed that in these conditions, the films were structurally weakened. At neutral $\mathrm{pH}$, the amine residues of chitosan would remain mostly deprotonated, not being available to interact with the free negatively charged carboxyl groups of xanthan, resulting in greater mass loss of the membrane. However, weight losses of up to $35 \%$ after six days of incubation in cell culture medium is acceptable and even desirable for absorbable devices (Bellini et al. 2012), because at this degradation rate, the biomaterial would remain stable in the body long enough to allow concomitant tissue regeneration.

Mass transport of large and small molecular species to and from the inner structure of hydrated xanthan-chitosan membranes could be related to mass transfer in gels, given their high absorption of some of the fluids tested, especially water. Since the mixture of chitosan and xanthan promotes the immediate formation of a polyelectrolyte complex, the structure of the matrix is possibly comparable to that of alginate 
gels internally reticulated with calcium ions. Also, given that the kinetics of binding of chitosan amino groups to xanthan carboxyl groups is fast, inhomogeneous molecular distribution might be somehow expected. Different mass transport mechanisms can be observed in gels and other similar structured materials, such as hydrodynamic flow, capillary flow, and molecular self-diffusion (Hermansson 2008; Schuster et al. 2014), depending on their structure. While hydrodynamic flow is observed in large and open structures, being driven by forces such as gravity and differences in chemical potential, capillary flow is noticed in gels with smaller pores and channels. In gels with pores of nanometric dimensions, diffusion is the dominant mechanism for the transport of water and other small molecules. If the gel has an open structure network not significantly obstructed by loose segment chains or molecules, the diffusion rate of small molecules in the matrix is not considerably affected. However, if pore obstruction is comparable to the dimension of the diffusing molecules, the transport rate may be significantly reduced (Hermansson 2008).

Based only on the endpoint experimental data of absorption and mass loss determined for the membranes exposed to the different physiological solutions, it is not possible to infer about the mass transport mechanisms of the tested molecular species in and out of the membranes. Further tests to elucidate the molecular structure of the membranes would be required for that. However, given that the membranes present high initial rates of solution absorption in the first min of exposure to the aqueous media, but stable plateau values are reached only after several hours, it can be assumed that the mass transfer mechanism of species going into the membranes probably changes with time due to modifications in the internal structure of the matrix during the swelling process. A similar assumption can be drawn from the mass loss data: the transference rate of loose polysaccharide chains from the interior of the matrix to the bulk solution potentially changed with time as a result of alterations in membrane molecular packing and organization.

\section{Characterization of the Films in vitro Cytotoxicity}

Besides the physico-chemical characterization of a bioactive dressing or scaffold, it is necessary to evaluate the cytotoxicity of the biomaterial, since during application it would be in direct contact with the cells. Figure 3 shows the results obtained in the in vitro toxicity tests of extracts prepared from C-X $X_{\text {pilot }}$ and C- $X_{\text {Keltrol }}$ films to L929 cells. The films produced showed minimal cytotoxic effects regardless of the type of xanthan used, in agreement with observations previously reported in the literature regarding biocompatibility and safety of the complex chitosan-xanthan gum in the form of microspheres for controlled drug release (Chellat et al. 2000) and even in comparison with dense or porous formulations prepared with analytical grade xanthan (Bellini et al. 2012).

These results indicated that xanthan from fermentation processes performed with different microbial strains and culture media could be more explored for the production of high added value materials such as those with direct use in the area of human health. Efforts in this direction would contribute to the expansion of the application fields of this biopolymer beyond the already wellestablished ones in various industrial sectors.

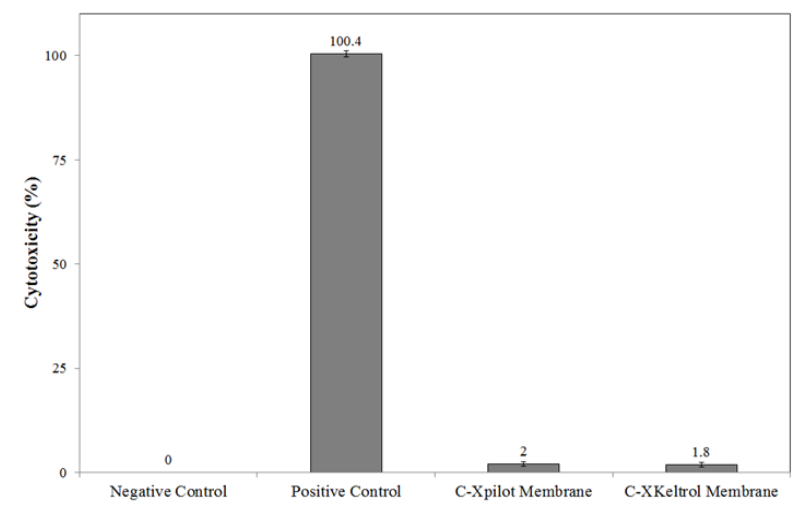

Figure 3 - In vitro cytotoxicity of the extracts of the films to L929 cells (0.05 g of C-X film per milliliter of supplemented RPMI culture medium). Extracts of culture plate fragments and of latex (in the form of amber tourniquet tubes regularly used in blood drawing) were used as negative and positive controls of cytotoxicity, respectively, and culture medium without cells was used as blank.

\section{CONCLUSIONS}

In this work, films prepared by combining chitosan to xanthan gum of different sources were analyzed and their physico-chemical and biological characteristics were compared aiming at applications in the therapy of skin lesions. The results showed that the type of xanthan gum used 
did not significantly affect most of the properties of the biomaterial obtained, even when the films were compared with the membranes of chitosan and xanthan gum of analytical grade. Thus, despite polymers of natural origin might present considerable variability depending on their provenience, the production of xanthan-gum based biomaterials seemed to show improved flexibility regarding the choice of raw materials and their suppliers, consequently expanding the opportunities for more economically attractive processes and biomaterials.

\section{ACKNOWLEDGEMENTS}

The authors thank the São Paulo Research Foundation (FAPESP, Brazil) and the IberoAmerican Programme for Science, Technology and Development (CYTED, Spain) for the support to this work, as well as the Coordination for the Improvement of Higher Educational Personnel (CAPES, Brazil) and the National Council for Scientific and Technological Development (CNPq, Brazil) for M. Z. Bellini's and Â. M. Moraes' fellowships, respectively.

\section{REFERENCES}

American Society for Testing and Materials ASTM D882-95a: Standard test methods for tensile properties of thin plastic sheeting, 1995.

Argin-Soysal S, Kofinas P, Lo YL. Food Hydrocolloids. 2014; 40: 138-144.

Bejenariu A, Popa M, Cerf DL, Picton L. Stiffness xanthan hydrogels: synthesis, swelling characteristics and controlled release properties. Polym Bull. 2008; 61: 631-641.

Bellini, MZ, Pires, ALR, Vasconselos MO, Moraes AM. Comparison of the Properties of Compacted and Porous Lamellar Chitosan-Xanthan Membranes as Dressings and Scaffolds for the Treatment of Skin Lesions. J Appl Polym Sci. 2012; 125: E421-E431.

Bueno C, Moraes AM. Development of porous lamellar chitosan-alginate membranes: effect of different surfactants on biomaterial properties. J Appl Polym Sci. 2011; 122: 624-631.

Carignatto RRC, Oliveira KSM, Lima VMG, OlivaNeto P. New culture medium to xanthan production by Xantomonas campestris pv. campestris. Indian J Microbiol. 2011; 51(3): 283-288.

Ceulemans J, Vinckier I, Ludwig A. The use of xanthan gum in an ophthalmic liquid dosage form: Rheological characterization of the interaction with mucin. J Pharm Sci. 2002 ; 91(4) : 1117-1127.
Chellat F, Tabrizian M, Dumitriu S, Chornet E, Magny $\mathrm{P}$, Rivard $\mathrm{CH}$, et al. In vitro and in vivo biocompatibility of chitosan-xanthan polyonic complex. J Biomed Mater Res. 2000; 51(1): 107-116.

Chen KY, Liao WJ, Kuo SM, Tsai FJ, Chen YS, Huang CY, Yao CH. Asymmetric Chitosan Membrane Containing Collagen I Nanospheres for Skin Tissue Engineering. Biomacromolecules. 2009; 10(6): 16421649.

Coma V. Polysaccharide-based biomaterials with antimicrobial and antioxidant properties. Polimeros. 2013; 23(3): 287-297.

Dallan PRM, Moreira PL, Petinari L, Malmonge SM, Beppu MM, Genari SC, et al. Effects of chitosan solution concentration and incorporation of chitin and glycerol on dense chitosan membrane properties. $J$ Biomed Mater Res Part B. 2007; 80B(2): 394-405.

Diniz DM, Druzian JI, Audibert S. Production of xanthan gum by Xanthomonas campestris strains native from bark cocoa or whey. Polímeros. 2012; 22(3): 278-281.

Dyondi D, Webster TJ, Banerjee R. A nanoparticulate injectable hydrogel as a tissue engineering scaffold for multiple growth factor delivery for bone regeneration. Int J Nanomed. 2013; 8: 47-59.

Eftaiha AF, El-Barghouthi MI, Rashid IS, Al-Remawi MM. Compressibility and compactibility studies of chitosan, xanthan gum, and their mixtures. $J$ Mater Sci. 2009; 44: 1054-1062.

Fernandes LL, Resende CX, Tavares DS, Soares GA, Castro LO, Granjeiro JM. Cytocompatibility of chitosan and collagen-chitosan scaffolds for tissue engineering. Polímeros. 2011;21(1): 1-6.

Fukuda H, Kikuchi Y. Polyelectrolyte complexes of chitosan with carboxymethyldextran. Bull Chemical Soc Japan. 1978; 511: 1142-1144.

Hansen B, Jemec GB. The mechanical properties of skin in osteogenesis imperfecta. Arch Dermatol. 2002; 138(7): 909-911.

Hermansson, A-M. Structuring water by gelation. In: Aguilera JM, Lillford P. Food Materials Science Principles and Practice. New York: Springer Science + Business Media, 2008. 255-280.

Izawa $\mathrm{H}$, Nishino $\mathrm{S}$, Maeda $\mathrm{H}$, Morita $\mathrm{K}$, Ifuku $\mathrm{S}$, Morimoto M, Saimoto H, Kadokawa JI. Mineralization of hydroxyapatite upon a unique xanthan gum hydrogel by an alternate soaking process. Carbohydr Polym. 2014; 102: 846-851.

Jayakumar R, Prabaharan M, Sudheesh Kumar PT, Nair SV, Tamura H. Biomaterials based on chitin and chitosan in wound dressing applications. Biotechnol Adv. 2011; 29(3): 322-337.

Jussila J, Leppäniemi A, Paronen M, Kulomäki E. Ballistic skin simulant. Forensic Sci Int. 2005; 150(1), 63-71.

Kokubo T, Kushitani H, Sakka S, Kitsugi T, Yamamuro T. Solutions able to reproduce in vivo surfacestructure changes in bioactive glass-ceramic A-W. $J$ 
Biomed Mater Res. 1990; 24(6): 721-734.

Kucharska M, Niekraszewicz A, Wišniewska-Wrona M, Brzoza-Malczewska K. Dressing sponges made of chitosan and chitosan-alginate fibrids. Fibres \& Textiles in Eastern Europe, 2008; 16(3): 109-113.

Kumar AS, Mody K, Jha B. Bacterial exopolysaccharides - a perception. J Basic Microbiol. 2007 ; 47(2): 103-117.

Lai HL, Abu'khalil A, Craig DQM. The preparation and characterization of drugloaded alginate and chitosan sponges. International Journal of Pharmaceutics. 2003; 251: 175-181.

Liu H, Mao J, Yao K, Yang G, Cui L, Cao Y. A study on a chitosan-gelatin-hyaluronic acid scaffold as artificial skin in vitro and its tissue engineering applications. J Biomater Sci Pol Ed. 2004; 15(1):2540.

Ludwig A. The use of mucoadhesive polymers in ocular drug delivery. Adv Drug Delivery Rev. 2005; 57: 1595-1639.

Ma J, Wang H, He B, Chen J. Biomaterials. 2001; 22(4): 331-336

Ma L, Gao C, Mao Z, Zhou J, Shen J, Hu X, et al. Collagen/chitosan porous scaffolds with improved biostability for skin tissue engineering. Biomaterials. 2003; 24(26): 4833-4841.

Malafaya PB, Silva GA, Reis RL. Natural-origin polymers as carriers and scaffolds for biomolecules and cell delivery in tissue engineering applications. Adv Drug Delivery Rev. 2007; 59: 207-233.

Mayer L, Vendruscolo CT, Silva WP, Moura AB. Production, rheological properties and chemical composition of xanthan produced by Xanthomonas axonopodis pv. phaseoli. Rev Bras Tecnol Agroind. 2008; 2: 87-94.

Oliva-Neto P, Lima VMG, Carignatto CRR, Carvalho AFA. Produção biotecnológica do biopolímero goma xantana. Microbiologia in foco. 2011; 4: 14-22.

Oliveira LHS, Dias FG, Duarte ICS, Oliva-Neto P, Cruz R, Moreira AS, et al. Isolamento e caracterização de bactérias produtoras de goma xantana. Rev Científica Plural. 2000; 1: 115-120.

Oliveira PD, Vendruscolo CT, Borges CD, Michel RC, Lomba RT. Comparative evaluation of xanthans properties produced by pathovar pruni and clairana with commercial xanthan to predict their uses. Polímeros. 2013; 23(3): 417-424.

Pajoum-Shariati SR, Shokrgozar MA, Vossoughi M, Eslamifar A. In vitro co-culture of human skin keratinocytes and fibroblasts on a biocompatible and biodegradable scaffold. Iran Biomedical J. 2009; 13(3): 169-177.

Popa N, Novac O, Profire L, Lupusoru CE, Popa MI. Hydrogels based on chitosan-xanthan for controlled release of theophylline. J Mater Sci Mater Med. 2010; 21: 1241-1248.

Ragetly GR, Griffon DJ, Chung YS. The effect of type II collagen coating of chitosan fibrous scaffolds on mesenchymal stem cell adhesion and chondrogenesis. Acta Biomater. 2010; 6: 3988-3997

Rodd AB, Dunstan DE, Ross-Murphy SB, Boger DV. Dependence of linear viscoelastic critical strain and stress values on extent of gelation for a thermally activated gelling system. Rheol Acta. 2001;40:23-29.

Rodrigues AP, Sanchez SEM, Costa AC, Moraes AM. The influence of preparation conditions on the characteristics of chitosan-alginate dressings for skin lesions. J Appli Polym Sci. 2008; 109: 2703-2710.

Santos JE, Soares JP, Dockal ER, Campana Filho SP, Cavalheiro ETG. Characterization of commercial chitosan from different suppliers. Polímeros. 2003; 13(4): 242-249.

Schuster E, Eckardt J, Hermansson A-M, Larsson A, Lorén N, Altskär A, et al. Microstructural, mechanical and mass transport properties of isotropic and capillary alginate gels. Soft Matter. 2014; 10: 357-366.

She Z, Jin C, Huang Z, Zhang B, Feng Q, Xu V. Silk fibroin/chitosan scaffold: preparation, characterization, and culture with HepG2 cell. J Mat Sci Mater Med. 2008; 19: 3545-3553.

Silva GA, Ducheyne P, Reis RL. Materials in particulate form for tissue engineering. Basic concepts. J Tissue Eng Regener Med. 2007; 1(1): 424.

Silva MLA, Crawford A, Mundy JM, Correlo VM, Sol $\mathrm{P}$, Bhattacharya $\mathrm{M}$, et al. Chitosan/polyester-based scaffolds for cartilage tissue engineering: assessment of extracellular matrix formation. Acta Biomater. 2010; 6: 1149-1157.

Veiga IG, Moraes AM. Study of the swelling and stability properties of chitosan-xanthan membranes. $J$ Appl Polym Sci. 2012;124: E154-E160.

Wang L, Khor E, Lim LY. Chitosan-alginate-CaCl2 system for membrane coat application. Journal of Pharmaceutical Sciences, J Pharm Sci. 2001; 90(8): 1134-1142.

Wang L, Khor E, Wee A, Lim LY. Chitosan-alginate PEC membrane as wound dressing: Assessment of incisional wound healing. J Biomed Mater Res. 2002; 63(5): 610-618.

Yan X, Khor E, Lim LY. PEC films prepared from chitosan-alginate co-acervates. Chem Pharm Bull. 2000; 48(7): 941-946

Yang B, Yin Z, Cao J, Shi Z, Zhang Z, Song H, et al. In vitro cartilage tissue engineering using cancellous bone matrix gelatin as a biodegradable scaffold. Biomed Mater. 2010: 5(4): 1-8.

Yin Y, Li Z, Sun Y, Yao K. A preliminary study on chitosan/gelatin polyelectrolyte complex formation. $J$ Mater Sci. 2005; 40: 4649-4652.

Zeng X, Ruckenstein E. Control of pore sizes in macroporous chitosan and chitin membranes. Ind Eng Chem Res. 1996; 35(11): 4169-4175.

Received: August 25, 2014; Accepted: December 26, 2014 